\title{
Social Media Use Among Library and Information Science Students: A Case Study
}

\author{
Mathias Gabriel Kasa ${ }^{1,2 *}$, Jamilu Muhammad Isah', Mohammed Shehu³, Shehu Allahde \\ Sunday Ladipo 5 \\ 'Department of Library and Information Science Faculty of Education, Ahmadu Bello University, Zaria, \\ Nigeria \\ ${ }^{2}$ Kashim Ibrahim Library, Ahmadu Bello University, Zaria, Nigeria \\ ${ }^{3}$ Nigeria Law School, Abuja Campus, Nigeria \\ ${ }^{4}$ College of Medicine and Health Sciences, Bingham University, Jos Campus, Plateau State, Nigeria \\ ${ }^{5}$ Medical Library, Lagos State University College of Medicine (LASUCOM) Ikeja, Lagos, Nigeria \\ "correspondence: mgkasa@abu.edu.ng
}

Received: 16 July 2021; Accepted: 23 September 2021; Published: 27 December 2021

\begin{abstract}
The purpose of this study is to identify the prevailing conditions of social media use among undergraduate students of Library and Information Science in a Nigerian University. Simple random sampling technique was used to select a sample of 180 full-time undergraduate students purposely. Descriptive statistics was used to analyze data collected through the administration of questionnaire. Research findings showed that a great number of students of Library and Information Science are addicted to social media for wrong academic purposes. The levels of addiction varied according to four Likert scale type. The highly addiction was among student using WhatApp $(40.82 \%)$ and not addicted among students using $\mathrm{BB}$ chat $(13.12 \%)$. The demographic indicators provided the obvious results of singles $(77.78 \%)$ possessing prevalence tendency of addiction, and surprisingly those between the ages of 27-30 (40\%) were most addicted. The paper recommends awareness programmes that are tailored to reveal the ills of social media addiction and pave ways to balance use of social media platforms that benefit academic activities among students.
\end{abstract}

Keywords: Addiction, LIS, social media use, information science

\section{INTRODUCTION}

The world is celebrating the use of information technology for dissemination of information. Among the benefits include turning the entire world into a "Global village", repositioning reactions and actions to available news lines and the critical information discourses. Both target and non-target audience are now reachable by the platforms, and significant number of people become better informed, enlighten, and capable of finding out any information of choice simply by clicking the buttons that connect social networking sites.

There are several social networking sites that people can subscribed depending on familiarity and interest or purpose of use. Among these social media sites is Twitter, Yahoo, Facebook, WhatsApp, 2go, Skype, and Linkedln. To students, these social networking sites help in various ways. Many uses them for learning and research, others for facilitating interaction and sharing of ideas. However, the growth and use of social networking sites are becoming overwhelming. For instance, statistics revealed that about two-third of the world's internet population visits and belong to the social media platforms and are transformed from the subscription to the online communities of internet users (Williams et al., 2009). Liccardi et al. 
(2012) point to benefits of these sites to students who connect for sharing their daily learning experiences and having conversations on several topics with the aim of understanding them.

There are also negative aspects of social media sites use by students. One of such effect is "addiction". According to Ratini (2019) Social media addiction is being overly concerned and behaviorally driven by an uncontrollable urge to log on to or use social media resulting to devoting so much time and effort to social media so much so that it impairs other important life areas. Most insinuations about addiction in the academic sphere and on students points to its use for "the wrong purposes". Social media addiction studies among students therefore are aimed at the end to provide insights on effects of putting social media to wrong academic use and what measures could redress such efforts. Vexed by repose expectation on these students who are old enough to prioritize their academic pursuit.

Kuppuswamy \& Narayan (2010), described social media addiction among students as "attention grabbing" so much so that it diverts them towards non-educational activities that is detrimental. Common uses of these sites primarily are for chatting. The internet usage and indeed effect of social media platforms in views of Nielsen (2012) on students was devoting more time on the social media for non-educational compared to education use. The statistics gave an approximate time spent on social media across mobile devices increased by $37 \%$ globally with about 121 billion minutes spent in July 2012 compared to 88 billion minutes spent in July 2011.

Tinto (2014) was perturbed about the discriminate use of social media most for extracurricular activities among students even when academic activities are introduced onto the platform. This implied that not substantial students use the platforms readily and end themselves with social media isolation. However, the smarter ones among them are observed to use their social networks for facilitation purposes such as seeking and gaining access to information and shared learning experiences to improve and help them attain academic performance.

\section{Study area}

The Ahmadu Bello University, Zaria, Nigeria is one of the first-generation universities in Nigeria. The university opens for students in 1962 and the second library school to start admitting students in 1968, and the first to offer the bachelor of Library Studies as its basic professional programme in Nigeria (Kasa \& Umar, n.d).

The restructuring of the undergraduate and postgraduate programs was done simultaneously to include the use of information and communication technology which was approved by the Faculty Board of Education, the University Senate and the Nigeria University Commission in 1989 which necessitated the renaming of the department from department of library studies to department of library and information science (ABUMIS, 2015).

The introduction of computer-based test in the 2012/2013 academic session could be said to encourage the developmental needs of student competence to utilize ICT supported social media dominated platform in the department (Kasa \& Auwalu, 2018). These students experience throughout the undergraduate program is imperative to understand the behavioral changes and emotional attributes on the matter of addiction to social media assessment studies.

\section{Problem statement}

Social media use is multifaceted in the life of undergraduate studies, it could be for formal and informal purposes in the student academic pursuits. This means, the more students use social media, the more they influence their disposition to studies, what these have amount to in terms of addiction for students of Library and Information Science is pertinent to investigate, particularly which medium and what demography constitute on the use of social media.

\section{Objectives of the Study}

The purpose of the paper is to determine the addiction of Library and Information Science students to social media. Specifically, the study seeks to:

1. find out the various levels of social media addiction of LIS students of Ahmadu Bello University, Zaria, and 
2. ascertain the demographic dispositions of respondents as pointer to the addiction of social media use by LIS students' of Ahmadu Bello University, Zaria.

\section{LITERATURE REVIEW}

Social media has a broad connotation, what is prominent in the numerous concepts is that it is that social media employed mobile and web-based technologies to create highly interactive platforms, individual(s) and community shared ideas, it could be used for discussions and modified user-generated content (Kietzmann et al., 2012). Social media technology includes the blogs, picture sharing, music sharing, crowd sourcing, e-mail, instant messaging and voice over. These are services providing platforms and could be integrated using supported aggregation platforms. Therefore, it is a phrase being tossed around a lot. Distinctively, however, it is also described as website that give information and interact when employed for the purpose of disseminating, processing, and harnessing information.

Kaplan \& Haenlein (2012) are of the opinion that social media is a group of internetbased application that builds on the ideological foundation and allows the creation and exchange of users (generated content and context). Social media platforms such as Facebook, WhatsApp, 2 go, BB chat, blogger and wiki have become one of the major channels of communication. Kaplan \& Haenlein (2010) classified social media into six different classes as follow: "Collaborative project (Wikipedia), Blogs and micro blogs (Twitter), Content communities (YouTube), Social networking site (Facebook, WhatsApp, 2go, and BB chat)". The specifications of social media platforms by them showed that all the categories can facilitate undergraduate student to attain graduate objective. According to Jamilu, Kasa \& Okoli (2017) social media influence academic performance of students of Library and Information Science in the 21st century. They found that most of the students investigated use WhatsApp (41.7\%) for interacting on academic and non-academic purposes, Facebook was used by $36.7 \%$, and the least users were those using 2 go (1.1\%) among five social media platforms investigated.

Addiction to social media according to Nielsen (2012) could be quantified on the "quantum of time students continues to spend on the platform for non-academic activities compared with the times for academic activities". Meanwhile, what cause addiction to social media sites has been enumerated by Tapscott (2008) to comprise the attraction of the social media site, its features that constantly allow subscribers to modify, upload pictures, add contents and update status. Educational supports are also enjoyed through surfing into and accessing educational resources. Defining social media addiction within the context of this study agrees with Andreassen \& Pallesen's (2014) who defined addictive characteristic on the social media as "being overly concerned about online activities, driven by an uncontrollable motivation to perform the behavior, and devoting so much time and effort to it that it impairs other important life areas" (p. 4054). Kuss \& Griffiths (2011) identified Facebook and Twitter as the most addictive social media sites; perhaps because of their spellbinding characteristics and that many students have smartphones that make utilizing them highly immediate. Addiction is caused by the obsession-built overtime by students who use the social media. Itodo in Olowu \& Seri (2012) averred that social media addiction is fast affecting student's academic, social and spiritual life. Mayilammal \& Mariammal (2014) and Mesch (2009) shared the concerns of parent whose complaints is that, children attention is severely taken away by social media sites at the children detriment.

Consequence of students' addiction to social media affects their behavior and could result to psychological disorder (Wang et al., 2018). Dangerous tendencies of addiction are the common sighting of students chatting during lectures, or carried away while walking along the busy traffic and chatting. Addiction to non-academic related use of social media during academic related times could result to loss of quality time and productive academic venture to a student.

Demographic factors such as age and marital status used for the assessment of respondents could help understand the implications of information elicited on addiction of library and information science students beyond intellectual and physical description. Because social media 
enable users to create profiles and content, articulate list of their users and views, comments, like and disapprove shared information, it is no doubt motivated by behavior, attitude and altitude. This makes demography underpinning an essential data source that could be tied to immensely important attributes of respondents. Akin (2017) attribute the lack of age discrimination and capacity to continually provide services among Twitter users to make it highly addictive.

Siibak (2009) opined that understanding the [demography of] social media user has helped to build adolescent identities such as the haste with which these personalities promote and provide response "real-time". Facebook is a social media site where anyone "who claims to be at least 13 years old" could become a registered user. These age group after registering can then join "common-interest groups" organized by school, friends and workplaces (Irwin et al., 2012). Bello cited in Olowu \& Seri (2012) opined that the social media can be inferred as floodgate, even though so open to all age-group of teenagers should require supervisory measures to help the young minds not to carve out for themselves world of fantasy and illusion leading to ruins. Earlier, McQuail (2020) argued that such measure can be those that mediate on the several emerging relationships particularly those described as "shift from visible to invisible friends". These measures should reorient towards study and writing, balanced psychological, world view and achieve set goals as students.

In Nigeria, demographic studies have revealed perturbing realities about the negative changes caused by social media among most age groups. In the case of studies, most age-groups spend more times online than studying, and are gradually getting to the point of obsession with the social media (Oluwu \& Seri, 2012). It was also reported that university drop-out has increased as a result of not attaining the minimum pass grade, and could be attributable to the students preoccupied with social media sites for the wrong purposes. It was reported by Bowen (2012) that the dropout in Nigeria could cause a national problem when left unabated.

\section{METHOD}

The study adopted survey research design of the quantitative method. The choice of the design conformed with the suggestions advanced by Pilkington \& Pretorius (2015) that research design should be adopted with the understanding that it could guide, identify and describe the overall study. Furthermore, the design has been described as efficient and ease to use when collecting data that can be described and interpreted using structured questionnaire and direct interviews (Creswell, 2014). The structured questionnaire used for data collection was called "Social Media and Academic Students' Performance (SMAAPOS), it comprised of four sections (A, $B, C$, and D) that were found to be adequate, comprehensible, and without prejudice to elicit opinion of 400 levels students of LIS on social media and academic performance after careful subjection to surface and structural validity.

The measurement grid relied on the Likert Scale Type. Data collection started after obtaining the total number of the 2017/2018 graduating students from the Ahmadu Bello University Management Information Unit (ABUMIS) of the academic office after using a letter of introduction from the head of LIS department. A total of 270 students were listed, these number was not too large and were completely enumerated. This agrees with the submission of Gall and Borg (2007) who advised that population in tens should be completely enumerated, between 2000 - 5000, a minimum of ten percent $(10 \%)$ response rate may be used for generalization, $1000-2000,20 \%$ may be used, while in hundreds, $50 \%$ may be used for the generalization of findings.

The administration of data collection instruments was done during lecture periods and the students were to returned the filled questionnaire three days after to the same venue. However, of the 270 questionnaires administered for data collection administered, only 180 copies were return. These number amounted to $66 \%$ response rate was substantial for generalization. The retrieved questionnaires were analysed descriptively and the results presented using their respective frequency counts and percentages. 


\section{RESULT AND DISCUSSION}

The results of the analysed data are described, presented and discussed from the questionnaire distributed and in line with the set study objectives starting with the levels of social media addiction and immediately followed by the demographic dispositions of the students.

Table 1. Levels of social media addiction of LIS students of Ahmadu Bello University, Zaria

\begin{tabular}{cccccccccc}
\hline $\begin{array}{c}\text { Most } \\
\text { patronize } \\
\text { social } \\
\text { media }\end{array}$ & $\begin{array}{c}\text { Highly addictive } \\
\text { (HA) }\end{array}$ & \multicolumn{2}{c}{ Addictive (A) } & $\begin{array}{c}\text { Levels of addiction* } \\
\text { Highly not } \\
\text { addictive (HNA) }\end{array}$ & \multicolumn{2}{c}{$\begin{array}{c}\text { Not addictive } \\
\text { (NA) }\end{array}$} \\
\cline { 2 - 11 } & Freq. & $\%$ & Freq. & $\%$ & Freq. & $\%$ & Freq. & $\%$ \\
\hline WhatsApp & 140 & 40.82 & 35 & 15.63 & 3 & 2.44 & 2 & 6.06 \\
Twitter & 83 & 24.20 & 78 & 34.82 & 13 & 10.57 & 6 & 18.18 \\
Facebook & 75 & 21.86 & 68 & 30.35 & 27 & 21.95 & 13 & 39.40 \\
BB Chart & 45 & 13.12 & 43 & 19.20 & 80 & 65.04 & 12 & 36.36 \\
\hline
\end{tabular}

Source: Survey, 2018; "Multiple response

The four social media platforms and their levels of addiction on LIS students is given in Table 1. The results revealed four Likert-scale type starting with highly addictive, addictive, highly not addictive and not addictive aided the description of results. The students attested that they are addicted most to use of WhatsApp $(40.82 \% \mathrm{HA}$; and $15.63 \% \mathrm{~A})$ compared with those who claimed they HNA (2.44\%), and NA (6.06\%), respectively for formal and informal purposes. Twitter is the second social media that addict LIS students. For HA $24.20 \%$ was recorded, A (34.82\%) whereas for HNA (10.57), and NA (18.18\%).

Facebook is the third social media platform that addict LIS students, it recorded frequency of $75(21.86 \%)$ for HA and for A (68 (30.35\%). The HNA revealed frequency of $27(21.95 \%)$ and NA 13 (39.40\%). However, BB Chart was the least with HA and A combined. It recorded the most scores for HNA (65.04\%) and next with the most scores for NA (36.36\%). These findings suggest that LIS student have different online and offline experiences that could be behaviourally categorized. This corroborates with other studies on social media addiction. Most authors on social media addition enumerated the liable offline behaviours that are inimical (Sapiezynski et al., 2018; Nesi et al., 2018) is not limited to clique-forming (Chan, 2020), encroachment - privacy issues (Beigi, \& Liu, 2020; Nazemzadeh, 2021), and concurrent sleep deprivation (Damota, 2019; Kartal, 2018), posting of false information about self and about others (Ghanem et al., 2020). The result therefore implied that there are variations behaviourally to the levels of LIS students' addiction due to both online and offline causes, and therefore a menace to academic performance.

Table 2. Demographic dispositions of respondents as pointer to the addiction of social media use by LIS students' of Ahmadu Bello University, Zaria

\begin{tabular}{lcc}
\hline Age & Frequency & Percentage \\
\hline $19-22$ & 66 & 36.7 \\
$23-26$ & 25 & 13.9 \\
$27-30$ & 72 & 40.0 \\
$31-36$ & 15 & 8.3 \\
37 and above & 2 & 1.1 \\
\hline Total & 180 & 100 \\
\hline Marital status & & \\
\hline Single & 140 & 77.78 \\
Married & 40 & 22.22 \\
\hline Total & 180 & 100 \\
\hline
\end{tabular}

Source: Survey, 2018 
The demographic results of LIS students are presented in Table 2. It is focused on two factors - age of LIS students and their marital status. These two factors have been used to assess the disposition of students towards the use of technologies. The choice of these two was not to discriminate but to allay the implications of these factors towards addiction and perhaps the "responsibility consciousness" that could be attributable to roles of age and marital status.

The table revealed that majority of the LIS students were within the age bracket of 27-30 $(72,40 \%)$ which within the Nigerian context could be grouped as matured individuals that may likely not depend on parents and guardians for their upkeep. Closely following are the age groups of $19-22$ (66, 36.7\%), and $23-26$ (25, 13.9\%) who are largely dependent on parents and guardian for their upkeep. Those within the age group $31-36$ (15, 8.3\%), and 37 and above $(2,1.1 \%)$ are matured. The implication of these frequency scores could be attributed to tendency to espouse the social media platforms by age which can cause addictiveness. The marital status could be argued to justify the addiction recorded among the LIS students when tied to marital-based responsibilities. For instance, majority of the LIS students were single (140, $77.78 \%)$ against the married ones (40,22.22\%). We are insinuating that being single and very young without marital-based responsibilities could be responsible for the spending of valuable time on social; media sites than on other things (poor prioritization) that is leading to addiction, other reasons could be the readiness to explore the social media sites to register and justify the feeling of "belongingness" caused by peer group pressure.

The two factors investigated by the study can espouse the relationship between the most addictive social media platforms and demography of the LIS students towards also pointing to the role of the introduction of computer-based related teaching, learning and test by the department. For instance, age has direct impact on addiction according to numerous literature on social media sites addiction (Andreassen et al., 2016; Pulido et al., 2020) because of its affiliatedrelatedness. These motives cause the exposition by LIS students who have during their formative years use the technologies perhaps because many of them were born during the technology driven period, and the tendency to use the technology as they are aged may not be immediate. Accordingly, LIS students' ages could point to the proneness to use social media platforms and predictable addictiveness (as affirmed as influence of age (adolescence) by Andreassen et al., 2016, p. 257).

Being married or single also influence the addictive tendencies of LIS students. Literature established that "not being in a relationship positively associate with social media addictive behaviours (David, \& Warrier, 2021; Solemet al., 2021). Thus, for most of the LIS students being single show the tendency to venture into social media and become addicted is possible when overzealously engaged to for different reasons that could lead to addiction. Study by Lemmens, et al. (2011) found that overcoming loneliness among singles was responsible for social media addiction in the quest to obtain companionship. Among married persons, David \& Warrier (2021) found that social media engagements metamorphosed into addiction when partners deploy it as relief to worries associated with demand of being married.

\section{CONCLUSION}

It could be concluded that students' use of social media has come to stay and that care must be taken so that it does not becloud them from prioritizing the purposes of use. Social media use among LIS students is highly addictive and can significantly influence the students causing tendencies such as distraction, psychological issues and taking most of LIS student productive time which with deliberate effort and understanding of the student levels and addiction and demographic disposition can be controlled. Negative energy expended by the students against productive time can be redressed. 


\section{RECOMMENDATIONS}

In the light of the findings and conclusion, the following recommendations are made:

1. Lecture notes, assignments and lecturer-students, student-student discussions (formal and informal) should better manage their encouraged using the social media platforms, as well as migrate activities that can flourish teaching and learning particularly those supported by Web 2.0 (interactive platform) against loosing productive academic time.

2. Awareness creation programmes targeted at motivating LIS students using the numerous social media sites irrespective of the age-group support and marital status should be considered in LIS curriculum to make it enticing for LIS students acquire corresponding soft skills aligned to the profession and relevant to LIS practice haven acquaint with the different programmes leading to LIS hard skills.

\section{REFERENCES}

ABUMIS (Ahmadu Bello University Management Information Services) (2015). Statistics of Students in the Department of Library and Information Science, Faculty of Education, Zaria Campus. 6p.

Akin, M., (2017). A research on the impacts of the young people's Internet addiction levels and their social media preferences. International Review of Management and Marketing, $7(2)$, 256-262.

Andreassen, C. S., \& Pallesen, S., (2014). Social network site addiction: An overview. Current Pharmaceutical Design, 20, 4053-4061. https://doi.org/10.2174/13816128113199990616

Andreassen, C. S., Billieux, J., Griffiths, M. D., Kuss, D. J., Demetrovics, Z., Mazzoni, E., \& Pallesen, S., (2016). The relationship between addictive uses of social media and video games and symptoms of psychiatric disorders: A large-scale cross-sectional study. Psychology of Addictive Behaviors, 30(2), 252.

Beigi, G., \& Liu, H. (2020). A survey on privacy in social media: identification, mitigation, and applications. ACM Transactions on Data Science, 1(1), 1-38. https://doi.org/10.1145/3343038

Bowen, G. (2012). Preventing school dropout: The eco-interactional developmental model of school success. The Prevention Researcher, 16(3), 3 - 9.

Chan, L. W. (2020). Social Media and Depression (Doctoral dissertation, Tunku Abdul Rahman University College).

Creswell, J. W. (2014). Research design: Qualitative, quantitative, and mixed methods approaches. SAGE, Thousand Oaks, 4th edition.

Damota, M. D. (2019). The Effect of social media on society. New Media Mass Communication, 78. DOI: $10.7176 / \mathrm{NMMC} / 78-02$

David, S., \& Warrier, U. (2021). Social media addiction among Indian young adults during Covid19. Parikalpana: KIIT Journal of Management, 17(1), 160-184. DOI:10.23862/kiitparikalpana/2021/v17/i1/209027

Ghanem, B., Rosso, P., \& Rangel, F. (2020). An emotional analysis of false information in social media and news articles. ACM Transactions on Internet Technology (TOIT), 20(2), 1-18. https://doi.org/10.1145/3381750 
Irwin, C., Ball, L., Desbrow, B., \& Leveritt, M., (2012). Students' perceptions of using Facebook as an interactive learning resource at university. Australasian Journal of Educational Technology, 28(7). https://doi.org/10.14742/ajet.798

Jamilu I. M., Kasa, M. G. \& Okoli, A.C. (2017). Influence of Social Media on the Academic Performance of Students of Library and Information Science in the $21^{\text {st }}$ Century. Library and Information Management Forum, 19(1\&2),104-112.

Kaplan, A. M., \& Haenlein, M., (2010). Users of the world, unite! The challenges and opportunities of Social Media. Business horizons, 53(1), 59-68. https://doi.org/10.1016/j.bushor.2009.09.003

Kaplan, A. M., \& Haenlein, M. (2012). Social media: back to the roots and back to the future. Journal of Systems and Information Technology. https://doi.org/10.1108/13287261211232126

Kartal, O. Y. (2018). Analysis of Alienation in Informal Education: Media Skepticism and Spiral of Silence in the Network Society. International Journal of Higher Education, 7(4), 110-122.

Kasa, M. G. \& Umar, I. (n.d). The extent of e-resources in the bibliographics of postgraduates' theses of the department of library and information sciences, Ahmadu Bello University, Zaria, 15p.

Kasa, M. G., \& Auwalu, Y. (2018). Imperative of Computer Base Test (CBT) on Performance of LIS Students: A Case Study. Library Philosophy and Practice, 1-12.

Kietzmann, J. H., Silvestre, B. S., McCarthy, I. P., \& Pitt, L. F. (2012). Unpacking the social media phenomenon: towards a research agenda. Journal of public affairs, 12(2), 109-119. https://doi.org/10.1002/pa.1412

Kuppuswamy, S. \& Narayan, P., (2010). The Impact of Social Networking Websites on the Education of Youth. International Journal of Virtual Communi ties and Social Networking (IJVCSN), 2(1), 67-79. DOI: 10.4018/jvcsn.2010010105

Kuss, D. J., \& Griffiths, M. D., (2011). Online social networking and addiction-a review of the psychological literature. International journal of environmental research and public health, 8(9), 3528-3552. https://doi.org/10.3390/ijerph8093528

Lemmens, J. S., Valkenburg, P. M., \& Peter, J., (2011). Psychosocial causes and consequences of pathological gaming. Computers in Human Behavior, 27, $144-152$. http://dx.doi.org/10.1016/j.chb.2010.07.015

Liccardi, I., Ounnas, A., Pau, R., Massey, E., Kinnunen, P. Lewthwaite, S, Midy, A., \& Sakar, C., (2012). The role of social networks in students' learning experiences. ACM SIGCSE Bull, 39(4), 224-237. https://doi.org/10.1145/1345375.1345442

Mayilammal, R., \& Mariammal, A., (2014). Study on usage and impact of social networking sites among students in Alangulam Taluk. Global Research Review in Business and Economics, $1(1)$.

McQuail, D., \& Deuze, M. (2020). McQuail's media and mass communication theory. Sage.

Mesch, G., (2009). Parental mediation, online activities, and cyber bullying. Cyber Psychology and Behavior, 12, 387-392. https://doi.org/10.1089/cpb.2009.0068 
Nazemzadeh, M. (2021). Social Media and Privacy Issues. Women in Ophthalmology; Weng, CY, Berrocal, AM, Eds.; Springer: Cham, Germany, 319-326. https://doi.org/10.1007/978-3030-59335-3

Nesi, J., Choukas-Bradley, S., \& Prinstein, M. J. (2018). Transformation of adolescent peer relations in the social media context: Part 1-A theoretical framework and application to dyadic peer relationships. Clinical Child and Family Psychology Review, 21(3), 267-294. https://doi.org/10.1007/s10567-018-0261-x

Nielsen, A. C., (2012). State of the media-The Social Media Report 2012. Incite. Know the Customer. $\quad h t t p: / / w w w . n i e l s e n . c o m / u s / e n / i n s i g h t s / r e p o r t s / 2012 /$ state-of-themedia-thesocial-media-report-2012. html.

Olowu, A. O., \& Seri, F. O., (2012). A study of social network addiction among youths in Nigeria. Journal of Social Science and Policy Review, 4(1), 63-71.

Pilkington, C., \& Pretorius, L. (2015, November). A Conceptual Model of the Research Methodology Domain. In KEOD (pp. 96-107).

Pulido, C. M., Mara, L. C., lonescu, V., \& Sordé-Martí, T. (2020). Social impact of psychological research on well-being shared in social media. Frontiers in Psychology, 11, 135. https://doi.org/10.3389/fpsyg.2020.00135

Ratini, M. (2019). Is Video Game Addiction Real? (para. 6). WebMD Medical Reference. Pridobljeno iz https://www. webmd. com/mental--health/addiction/video-gameaddiction, 1.

Sapiezynski, P., Stopczynski, A., Wind, D. K., Leskovec, J., \& Lehmann, S. (2018). Offline behaviors of online friends. arXiv preprint arXiv:1811.03153.

Siibak, A., (2009). Constructing the self through the photo selection-visual impression management on social networking websites. Cyberpsychology: Journal of psychosocial research on cyberspace, 3(1).

Solem, S., Pedersen, H., Nesse, F., Garvik Janssen, A., Ottesen Kennair, L. E., Hagen, R., ... \& Spada, M. M. (2021). Validity of a Norwegian version of the Desire Thinking Questionnaire (DTQ): Associations with problem drinking, nicotine dependence and problematic social media use. Clinical Psychology \& Psychotherapy, 28(3), 615-622. https://doi.org/10.1002/cpp.2524

Tapscott, D., (2008). Grown up digital. Boston: McGraw-Hill Education.

Tinto, V., (2014). Classrooms as communities: Exploring the educational character of student persistence. Journal of Higher Education, 68(6), 599 - 623. https://doi.org/10.1080/00221546.1997.11779003

Wang, P., Lei, L., Wang, X., Nie, J., Chu, X., \& Jin, S., (2018). The exacerbating role of perceived social support and the "buffering" role of depression in the relation between sensation seeking and adolescent smartphone addiction. Personality and Individual Differences, 130, 129-134. https://doi.org/10.1016/j.paid.2018.04.009

Williams, K., Boyd, A., Densten, S., Chin, R., Diamond, D., \& Morgenthaler, C. (2009). Social networking privacy behaviors and risks. Seidenberg School of CSIS, Pace University, USA. 
Copyright (c) 2021 by the authors. This work is licensed under a Creative Commons Attribution-ShareAlike 4.0 International License. 